\title{
Identifying high risk areas of Zika virus infection by meteorological factors in Colombia
}

\author{
Lung-Chang Chien ${ }^{*}$ D , Francisco Sy ${ }^{1}$ and Adriana Pérez ${ }^{2}$
}

\begin{abstract}
Background: Several Zika virus (ZIKV) outbreaks have occurred since October 2015. Because there is no effective treatment for ZIKV infection, developing an effective surveillance and warning system is currently a high priority to prevent ZIKV infection. Despite Aedes mosquitos having been known to spread ZIKV, the calculation approach is diverse, and only applied to local areas. This study used meteorological measurements to monitor ZIKV infection due to the high correlation between climate change and Aedes mosquitos and the convenience to obtain meteorological data from weather monitoring stations.

Methods: This study applied the Bayesian structured additive regression modeling approach to include spatial interactive terms with meteorological factors and a geospatial function in a zero-inflated Poisson model. The study area contained 32 administrative departments in Colombia from October 2015 to December 2017. Weekly ZIKV infection cases and daily meteorological measurements were collected. Mapping techniques were adopted to visualize spatial findings. A series of model selections determined the best combinations of meteorological factors in the same model.
\end{abstract}

Results: When multiple meteorological factors are considered in the same model, both total rainfall and average temperature can best assess the geographic disparities of ZIKV infection. Meanwhile, a 1-in. increase in rainfall is associated with an increase in the logarithm of relative risk (logRR) of ZIKV infection of at most 1.66 (95\% credible interval $[\mathrm{CI}]=1.09$, 2.15) as well as a $1^{\circ} \mathrm{F}$ increase in average temperature is significantly associated with at most $0.79(95 \% \mathrm{Cl}=0.12,1.22)$ increase in the logRR of ZIKV. Moreover, after controlling rainfall and average temperature, an independent geospatial function in the model results in two departments with an excessive ZIKV risk which may be explained by unobserved factors other than total rainfall and average temperature.

Conclusion: Our study found that meteorological factors are significantly associated with ZIKV infection across departments. The study determined both total rainfall and average temperature as the best meteorological factors to identify high risk departments of ZIKV infection. These findings can help governmental agencies monitor at risk areas according to meteorological measurements, and develop preventions in those at risk areas in priority.

Keywords: Zika virus infection, Meteorological factors, Geographic disparities, Colombia

\footnotetext{
* Correspondence: lung-chang.chien@unlv.edu

${ }^{1}$ Department of Environmental and Occupational Health, University of

Nevada, Las Vegas, School of Public Health, 4505 S. Maryland Parkway, Las

Vegas, NV 89154, USA

Full list of author information is available at the end of the article
}

(c) The Author(s). 2019 Open Access This article is distributed under the terms of the Creative Commons Attribution 4.0 International License (http://creativecommons.org/licenses/by/4.0/), which permits unrestricted use, distribution, and reproduction in any medium, provided you give appropriate credit to the original author(s) and the source, provide a link to the Creative Commons license, and indicate if changes were made. The Creative Commons Public Domain Dedication waiver (http://creativecommons.org/publicdomain/zero/1.0/) applies to the data made available in this article, unless otherwise stated. 


\section{Background}

Since October 2015, several outbreaks of Zika virus (ZIKV) have occurred in Central and South America, the Caribbean, Central Africa, and Southeast Asia [1, 2]. The infection of ZIKV may not be lethal, and most infected people may not feel very sick, with only mild symptoms [3]. Compared to the other vector-borne diseases transmitted by Aedes mosquitoes, such as dengue fever, yellow fever, or chikungunya, ZIKV infection may not be fatal. The predominant adverse impact of ZIKV infection affects infected pregnant women, who may give birth to infants with microcephaly [4]. Besides mosquitoes, ZIKV can also be transmitted through sexual contact, blood transfusion, and prenatally from mother-to-fetus transmission via pregnancy [5]. Because there is no effective treatment for ZIKV infection, developing an effective surveillance and warning system is currently a high priority to prevent ZIKV infection [6-8].

As a vector-borne disease, ZIKV is strongly associated with increases in the mosquito population. To prevent ZIKV infection, it is essential to break the transmission of the virus from mosquitoes to humans [9]. However, controlling the increase and distribution of vector population is difficult. Aedes mosquitoes grow in large numbers when the diurnal temperature is between 30 and $35^{\circ} \mathrm{C}$ (i.e., 86-95 ${ }^{\circ} \mathrm{F}$ ) [10] and with an optimal temperature to produce the most amount of offspring at $29.2^{\circ} \mathrm{C}$ (i.e., $84.56^{\circ} \mathrm{F}$ ) [11]. Similarly, rainfall may provide a favorable environment to increase the population of Aedes mosquitoes [12-14]. Climate change and the increased distribution of $A e$ des mosquitoes are positively correlated [15-17]. With the influence of climate change on diverse areas, the occurrence and distribution of vector-borne diseases, like ZIKV infection, may become more complicated and difficult to monitor.

Spatial analysis and geographic information systems have been used to investigate the distribution of ZIKV infection with related risk factors locally and globally. A study in Brazil, the first country in South America with ZIKV outbreaks, applied a maximum entropy method to analyze the location of observed cases [18]. This literature found that land use was the most important environmental factor to explain the spatial distribution of the risk probability of ZIKV infection. Similar spatial techniques were also applied to other ZIKV prevalent countries, especially in Central and South America. In Puerto Rico, the areas with the highest Zika rates were significantly associated with higher poverty, as identified by the geographically weighted regression [19]. A multicountry study identified nine main municipalities across Colombia, Ecuador, Mexico, and Peru (out of eight countries in Central and South America) as having an increased likelihood of ZIKV transmission by using multiple modeling approaches in ranking the median projected ZIKV infection rate [20]. Some studies applied spatial simulation methods to model potential transmission risk of ZIKV globally, and estimated that tropical and subtropical areas in four continents were experiencing higher risks of ZIKV infection in comparison to non-tropical areas [21, 22].

Since meteorological measurements are known to vary across different areas, there is a need to determine whether climate change will have different impacts on ZIKV infection. Our study aims are to evaluate the spatial association of climate change on ZIKV infection and to identify high-risk areas of ZIKV infection by specific meteorological measurements in Colombia. Our preliminary hypothesis is that the meteorological influence on ZIKV infection significantly varies across different areas. The models were compared to identify the best meteorological factor associated with high-risk areas of ZIKV infection. We also used mapping techniques to present the diverse meteorological influence on ZIKV infection, and to facilitate the inspection of hot zones representing where people were more vulnerable to ZIKV. These maps can clearly identify hot zones with vulnerable populations to ZIKV infection because of the chosen meteorological factor(s). Estimating ZIKV infections when a meteorological factor increased by a particular amount is important for both national and local surveillance systems to assess interventions to decrease the incidence of ZIKV cases.

\section{Methods}

\section{Data source}

We downloaded weekly reports of ZIKV infection cases from the Epidemiological Bulletin, maintained by the Colombian National Institute of Health with a total of 156 consecutive weeks from the 39th week of 2015 (the first week of reporting ZIKV infection) to the 52nd week of 2017. Daily meteorological measurements were fetched from 42 weather monitoring stations in Colombia reported on the Weather Underground (https://www.weatherunderground.com/). The study considered the following meteorological factors: temperature, dew point temperature, relative humidity, sea level pressure, wind speed, and total rainfall. Besides wind speed and total rainfall, each meteorological factor has three types of measurement: maximum, minimum, and average.

\section{Study area}

Colombia, the third-most populated country in Latin America, was selected to be the study area because it has very complete records of ZIKV infection cases reported by week and "department" (i.e., the largest administrative area unit and selected as the geographic unit of analysis). Colombia is on the equator, and has a 
very classical tropical climate with warm and isothermal weather condition. There are a total of 32 departments in Colombia (Fig. 1). Bogotá, the capitol of Colombia, is the most populated area and located within the Cundinamarca's department with over 10 million residents in 2018 [23], and it is 60\% larger than the population in the second populated department. In particular, the archipelago of San Andrés and Providencia is the only department composed of two small islands located in the east of the Caribbean Sea.

\section{Meteorological measurements}

A total of 42 weather monitoring stations are distributed among 32 departments, with 19 departments having multiple stations and 10 departments having only a single station. Only three departments did not have a monitoring station. The locations of all monitoring stations are presented in Fig. 1. In order to unify the time scale between ZIKV infection and meteorological factors as well as dealing with missing data in some of the meteorological factors, a series of data management and imputations were conducted. First, we integrated daily meteorological measurements in the 19 departments with multiple monitoring stations. For instance, daily maximum temperature in a department was determined by the largest value of daily maximum temperatures among all monitoring stations in the same department. Similarly, we adopted the same criterion to determine the daily minimum or average measurement of a meteorological factor by department. For rainfall, we used the maximum value of multiple daily rainfall records from all monitoring stations in a department. Second, we applied a local space-time kriging method to impute missing daily meteorological measurements among 29 departments with at least one monitoring station [24]. Third, we calculated weekly meteorological measurements in each of those 29 departments. Finally, we applied the local space-time kriging method again on the weekly meteorological measurements to impute missing data in the three departments without a monitoring station. The last step made a sample size of 156 weeks $\times 32$ department $=4992$ data points for each meteorological factor, which was merged with ZIKV infection data.

\section{Spatial modeling approach}

By defining $Y_{d t}$ as the number of ZIKV infection cases at time $t$ in department $d$, we assumed the distribution of $Y_{d t}$ as a Poisson distribution with a mean parameter $\mu_{d t}$. Initially, the mean parameter was analyzed using a Poisson model, but because of excessive zero counts in the data of ZIKV infection cases, the zero-inflated Poisson model was chosen. In particular, in order to evaluate the spatial association of meteorological factors on ZIKV infection, we applied a Bayesian structured additive regression modelling approach to incorporate both the zero-inflated Poisson model and the spatial components into account [25]. The mean parameter $\mu_{d t}$ is estimated by the following equation:

$$
\begin{aligned}
\log \left(\mu_{d t}\right)= & \alpha+f(t)+\beta(\text { Year })+(\text { Meteo }) \times f_{\text {mrf }}(d) \\
& +f_{g s p}\left(\text { lon }_{d}, \text { lat }_{d}\right)+\text { offset }, t \\
= & 1 \ldots, 156 ; d=1, \ldots, 32
\end{aligned}
$$

where $\alpha$ is the fixed intercept, and the offset is the logarithm of the population of each department. In order to control for temporal autocorrelations, the model contained a time smoother $f(\mathrm{t})$ by using a Bspline with the second order random walk prior, and

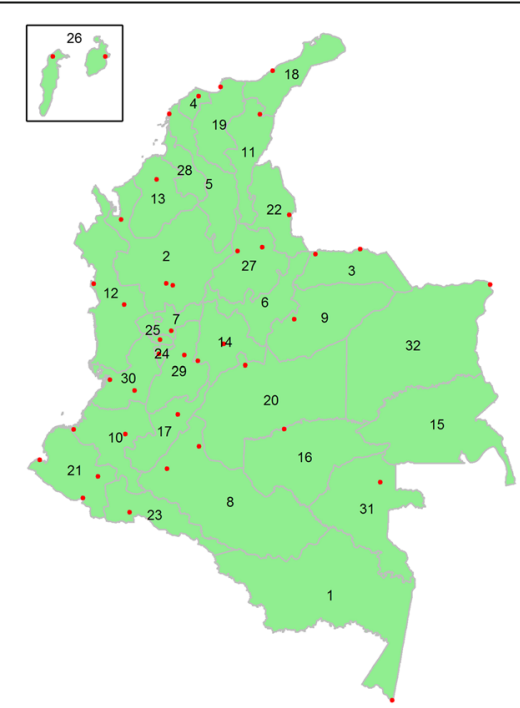

\begin{tabular}{|r|c|c|c|}
\hline ID & Department & ID & Department \\
\hline 1 & Amazonas & 17 & Huila \\
\hline 2 & Antioquia & 18 & La Guajira \\
\hline 3 & Arauca & 19 & Magdalena \\
\hline 4 & Atlántico & 20 & Meta \\
\hline 5 & Bolívar & 21 & Nariño \\
\hline 6 & Boyacá & 22 & Norte de Santander \\
\hline 7 & Caldas & 23 & Putumayo \\
\hline 8 & Caquetá & 24 & Quindio \\
\hline 9 & Casanare & 25 & Risaralda \\
\hline 10 & Cauca & 26 & San Andrés and Providencia \\
\hline 11 & Cesar & 27 & Santander \\
\hline 12 & Chocó & 28 & Sucre \\
\hline 13 & Córdoba & 29 & Tolima \\
\hline 14 & Cundinamarca & 30 & Valle del Cauca \\
\hline 15 & Guainia & 31 & Vaupés \\
\hline 16 & Guaviare & 32 & Vichada \\
\hline
\end{tabular}

Fig. 1 The boundaries of 32 departments and the locations of 42 weather monitoring stations in Colombia 
Year as a confounding variable with two levels in year 2016 and 2017 (i.e., year 2015 was the reference level). The term Meteo was a meteorological random effect interacting with a spatial function $f_{\text {mrf }}(d)$, which is the Markov random fields (MRF) to conduct a geographic weight in each department. Finally, the model included a geospline function $f_{g s p}\left(l o n_{d}, l a t_{d}\right)$ to evaluate the excessive risk of ZIKV infection which cannot be explained by meteorological factors, where $\left(\operatorname{lon}_{d}, l a t_{d}\right)$ is the centroid coordinate (longitude and latitude) of department $d$.

All unknown parameters in the model were estimated via Markov chain Monte Carlo simulations with 70,000 iterations based on a fully Bayesian inference. The first 20,000 iterations were burned, and we drew estimates from every 50 iterations out of the remaining 50,000 iterations [26]. Therefore, each parameter had 1000 estimates of the posterior distribution, where the posterior mean, the 2.5th and 97.5th percentiles are reported as the estimated parameter and $95 \%$ credible interval (CI), respectively. The posterior mean can be explained as the logarithm of relative risk $(\operatorname{logRR})$ for ZIKV infection, and the statistical significance of $\log R R$ was determined by whether the $95 \% \mathrm{CI}$ is strictly different from 0 .

The univariate analysis consisted of fitting a model with each meteorological factor to evaluate geographic disparities of ZIKV infection affected by each factor individually. Then, a multivariable model was built to consider at most three meteorological factors simultaneously. The best model was determined by the smallest deviance information criterion (DIC). We did not include highly correlated meteorological factors in the same model to prevent possible multicollinearity within each department. The spatial estimate in $f_{m r r}(d)$ represents the expected increase in the $\operatorname{logRR}$ of ZIKV infection for a one-unit increase in a meteorological factor in department $d$. The spatial estimate in $f_{g s p}\left(\operatorname{lon}_{d}\right.$, lat $\left._{d}\right)$ can be also regarded as a $\operatorname{logRR}$ to quantify the excessive risk of ZIKV infection of a department compare to the average of the whole Colombia after controlling for meteorological factors. The exponentiation of the standard deviation of the spatial estimated conducted by $f_{m r r}(d)$ (i.e., $\exp \left(\sqrt{\sigma_{M R F}^{2}}\right)$ ) can be explained as the average variation of relative risk due to the meteorological factor among 32 departments. Thus, a geographic disparity percentage (GD\%) can be calculated to explain the departmental ZIKV risk on average $\left(\exp \left(\sqrt{\sigma_{M R F}^{2}}\right)-1\right) \times 100 \%$ higher or lower than the overall ZIKV risk. The same way to quantify the level of geographic disparities was also applied in the geospatial function $f_{g s p}\left(\operatorname{lon}_{d}, l a t_{d}\right)$. A larger GD\% represents greater geographic disparities among 32 departments.

Data management and summary statistics were implemented in SAS V9.3 (SAS Institute Inc., Cary). Data imputation, model fitting, and mapping were implemented in the $\mathrm{R}$ software, version 3.5.0 [27] and BayesX version 2.0 [28].

\section{Results}

The summary statistics in Table 1 shows that the weekly average of ZIKV infection cases in Colombia was 21.33 cases (standard deviation $=101.28$ ), and can reach as high as 1750.00 cases, which occurred in Valle del Cauca. Extreme heat and rainfall, and high humidity were also observed from 2015 to 2017. Figure 2a shows that Valle del Cauca, Norte de Santander, and Santander reported over 10,000 cases of ZIKV infection from 2015 to 2017. Figure $2 b$ shows that a high crude incidence of ZIKV infection over 100 cases per 10,000 population appeared in the Islands of San Andrés and Providencia and the departments of Casanare and Arauca. The detailed values of each department in Fig. 2 can be referred to Additional file 1: Table S1. The weekly average of each meteorological measurement by the department is presented in Additional file 1: Fig. S1. The absolute Pearson correlation coefficients of the meteorological factors are greater or equal to 0.7 among all kinds of temperature, dew point temperature, and sea level pressure (see Additional file 1: Table S2).

We first evaluated the need of the independent geospatial function in our models, which results in, whichever meteorological factor in the model, having the geospatial function produced a lower DIC from 82,564.40 to 82, 787.98, while the models with the geospatial function had a higher DIC from 85,539.96 to 85,708.96. This result provides the support of appending the geospatial function to consider additional geographic disparities of ZIKV infection, which cannot be fully explained by the meteorological factors.

Table 2 shows the proportion of departments in terms of positive, negative and non-significant associations of the MRF univariately for each meteorological factor. A larger proportion of departments had a significant positive association between ZIKV infections and each one of the meteorological factors. For example, the average sea level pressure and the total rainfall were associated with increasing ZIKV infections on 17 departments (53.13\%). The largest meteorological impact on ZIKV infection was observed in Amazonas, where the expected increase in $\log R R$ for 1-mph increase in the maximum wind speed was $2.28(95 \% \mathrm{CI}=0.24,2.98)$. From the perspective of model evaluation, both the average temperature and average dew point temperature better assessed the geographic disparities of ZIKV infection because both models have the lowest DIC by $82,560.97$ and 82 , 558.50 , respectively.

In the univariate analysis, geographic disparities of ZIKV infection due to meteorological factors measured by GD\% diversely ranged from $252.27 \%$ due to maximum temperature to $328.93 \%$ due to average dew point temperature. Maps in Additional file 1: Figure S2 reveal 
Table 1 Descriptive statistics of weekly Zika virus infection cases and meteorological factors per department

\begin{tabular}{|c|c|c|c|c|c|c|c|}
\hline & Mean & SD & Min & Q1 & Median & Q3 & Max \\
\hline ZIKV cases & 21.33 & 101.28 & 0.00 & 0.00 & 0.00 & 3.00 & 1750.00 \\
\hline \multicolumn{8}{|l|}{ Temperature ( $\left.{ }^{\circ} \mathrm{F}\right)$} \\
\hline Maximum & 89.11 & 7.07 & 66.00 & 86.83 & 90.00 & 93.00 & 137.00 \\
\hline Minimum & 65.09 & 9.17 & 5.00 & 61.00 & 66.36 & 72.00 & 81.00 \\
\hline Average & 77.60 & 7.02 & 53.86 & 74.74 & 79.06 & 82.37 & 91.43 \\
\hline \multicolumn{8}{|c|}{ Dew point temperature $\left({ }^{\circ} \mathrm{F}\right)$} \\
\hline Maximum & 74.01 & 6.08 & 47.00 & 70.88 & 74.97 & 79.00 & 90.00 \\
\hline Minimum & 61.40 & 10.91 & 0.00 & 55.53 & 64.00 & 70.00 & 77.00 \\
\hline Average & 69.01 & 6.95 & 40.57 & 65.43 & 70.16 & 74.15 & 80.29 \\
\hline \multicolumn{8}{|l|}{ Relative humidity (\%) } \\
\hline Maximum & 96.35 & 5.01 & 61.00 & 94.00 & 100.00 & 100.00 & 100.00 \\
\hline Minimum & 41.03 & 11.97 & 4.00 & 33.21 & 42.96 & 50.00 & 73.00 \\
\hline Average & 73.19 & 8.94 & 31.29 & 68.86 & 74.57 & 79.25 & 93.14 \\
\hline \multicolumn{8}{|l|}{ Sea level pressure $(\mathrm{Hg})$} \\
\hline Maximum & 30.08 & 0.17 & 29.79 & 29.96 & 30.04 & 30.15 & 31.32 \\
\hline Minimum & 29.78 & 0.16 & 28.73 & 29.69 & 29.76 & 29.85 & 30.30 \\
\hline Average & 29.95 & 0.14 & 29.65 & 29.84 & 29.92 & 30.01 & 30.40 \\
\hline \multicolumn{8}{|l|}{ Wind speed (mph) } \\
\hline Maximum & 25.17 & 31.36 & 3.47 & 12.00 & 15.00 & 21.00 & 150.00 \\
\hline Average & 4.66 & 2.84 & 0.29 & 2.86 & 4.17 & 5.60 & 20.14 \\
\hline Total rainfall (inches) & 0.60 & 2.11 & 0.00 & 0.01 & 0.16 & 0.52 & 39.49 \\
\hline
\end{tabular}

Abbreviation: SD Standard deviation, Q1 The first quartile, Q3 The third quartile

that the meteorological influence on ZIKV infection had different levels of geographic disparities across 32 departments in Colombia. According to the corresponding significance maps shown in Additional file 1: Figure S3, most at-risk departments due to meteorological factors were located in the northern and eastern areas of Colombia. In addition, the southern areas of Colombia may be also at risk because of the minimum temperature, average relative humidity, maximum wind speed, and total rainfall. Four departments (Norte de Santander, Risaralda, Tolima, and Valle del Cauca) located in western Colombia were detected as at-risk areas by all 15 meteorological factors. On the contrary, 10 departments were never detected as at-risk areas by any of those meteorological factors, and most of them are located along the coast line of the Pacific Ocean and along the border of Brazil and Venezuela.

The multivariable analysis shows that both total rainfall and average temperature in the same model had the lowest DIC by 82,528 , which is much farther below the DICs of the two best models in the univariate analysis. Figure $3 \mathrm{a}$ shows that the association of total rainfall and ZIKV infection in the northern areas of Colombia. Twenty of 32 departments $(62.5 \%)$ had a positive association between total rainfall and ZIKV infection, while only 11 of them were statistically significant. Most of these 11 departments are located in northern Colombia, while Tolima located in central Colombia had the largest impact $(\operatorname{logRR}=1.66 ; 95 \%$ $\mathrm{CI}=1.09,2.15$ ). Figure $3 \mathrm{~b}$ presents a positive association between average temperature and ZIKV infection in northern and northeastern Colombia, while the significance map only reveals two departments having a significant positive impact on ZIKV: Magdalena $(\operatorname{logRR}=0.79 ; 95 \% \mathrm{CI}=0.12$, $1.22)$ and Arauca $(\log R R=0.62 ; 95 \% \mathrm{CI}=0.28,1.04)$. After controlling for both total rainfall and average temperature, 15 departments had a positive $\log R \mathrm{R}$ calculated from the geospatial function, revealing that those departments had excessive ZIKV risks, see Fig. 4a; however, Fig. 4b shows that only Arauca and Meta had a logRR significantly larger than 1. Comparing the two selected meteorological factors, the total rainfall resulted in a higher GD\% than average temperature (305.69\% vs. $10.99 \%)$.

\section{Discussion}

As the alarm of ZIKV has arose since 2015, the research on ZIKV vaccines and antiviral drugs is still being conducted, despite its severity has been gradually diminishing since 2017 [29]. Some preventive interventions have been implemented in different areas using the same vector control strategies applied to dengue fever, which is 

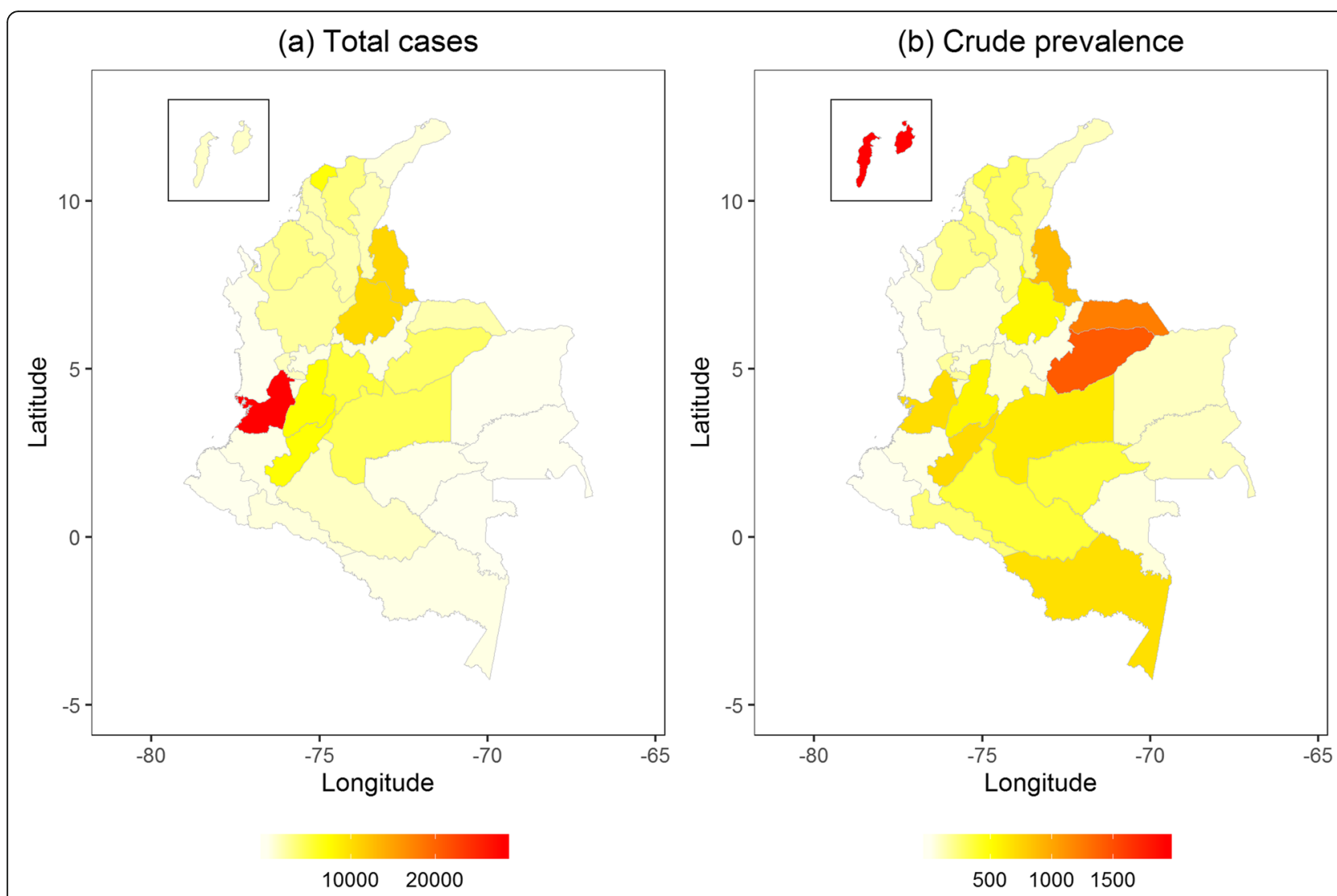

Fig. 2 The geographic distribution of (a) the total Zika virus infection cases and (b) the crude prevalence of Zika virus infection per 10,000 population by each department in Colombia from 2015 to 2017

also transmitted by Aedes mosquitoes [30]. Those strategies may not prevent the occurrence of outbreaks and cannot predict when an outbreak will occur. A systematic review in 2016 has pointed out the need to define the range of ZIKV vectors and to identify new areas where ZIKV transmission could take place to enable early transmission [31]. Our study provides a statistical approach to monitor climate change for quantifying the impact of ZIKV infection in a large area by meteorological measurements, which are collected in multiple weather stations routinely. Our main findings are: First, different meteorological factors can detect different atrisk areas, and total rainfall and average sea level pressure can aggressively detect more at-risk areas; second, when considering multiple meteorological factors in the same model, using both total rainfall and average temperature, can better detect at-risk areas; third, meteorological factors may not totally explain the variation of ZIKV infection, and there might be some other unobserved risk factors which may contribute to excessive ZIKV risk infection.

Temperature and rainfall have been linked to Aedes albopictus or Aedes aegypti population in literature [32, 33], while the direct evidence is still limited to link the association between ZIKV infection and the two meteorological factors. Our findings are consistent with the literature in vector-borne diseases and the population of Aedes albopictus or Aedes aegypti. We did not exclude the possibility that other meteorological measurements were associated with vector-borne diseases [34, 35]. This study proposed a systematic procedure to filter the best meteorological factors; however, for a more comprehensive and aggressive prevention on ZIKV, using the univariate model is still acceptable. In confronting emerging ZIKV outbreaks with limited time and resources available, public health officials will have to rely on the best meteorological factors as an option to determine where to focus their preventive interventions.

The literature has shown the geographic variations of ZIKV infection. For instance, a study analyzed individual ZIKV cases in Nicaragua, revealing a $10-15 \%$ difference in the risk of ZIKV infections across neighborhoods [36]. However, the study area in this research is relatively small at around $3 \mathrm{~km}^{2}$. A global health study applied the niche modelling techniques to estimate the potential geographic distribution area of Aedes aegypti, resulting in a high ZIKV risk concentration in the countries surrounding the Caribbean Sea and in the Atlantic 
Table 2 The summary of spatial estimates from the Markov random fields in terms of significant positive (the logarithm of relative risk (logRR) is significantly greater than 0), significant negative (logRR is significantly smaller than 0) and non-significane (logRR is not different from 0) and geographic disparity percentage in each meteorological factor based on the univariate analysis

\begin{tabular}{|c|c|c|c|c|c|c|c|c|}
\hline & \multicolumn{3}{|c|}{ Significant positive } & \multicolumn{2}{|c|}{ Significant negative } & \multicolumn{3}{|c|}{ Non-significance } \\
\hline & $\mathrm{N}$ & n (\%) & logRR range & $\mathrm{n}(\%)$ & logRR range & n (\%) & logRR range & GD\% \\
\hline \multicolumn{9}{|l|}{ Temperature } \\
\hline Maximum & 32 & $12(37.50)$ & $(0.29,2.00)$ & $7(21.88)$ & $(-4.00,-0.38)$ & $13(40.63)$ & $(-0.53,1.01)$ & 252.27 \\
\hline Minimum & 32 & $16(50.00)$ & $(0.51,1.73)$ & $9(28.13)$ & $(-4.61,-0.47)$ & $7(21.88)$ & $(-0.83,0.42)$ & 303.00 \\
\hline Average & 32 & $16(50.00)$ & $(0.42,1.98)$ & $9(28.13)$ & $(-4.85,-0.44)$ & $7(21.88)$ & $(-0.74,1.36)$ & 300.33 \\
\hline \multicolumn{9}{|c|}{ Dew point temperature } \\
\hline Maximum & 32 & $15(46.88)$ & $(0.34,1.84)$ & $7(21.88)$ & $(-4.65,-0.30)$ & $10(31.25)$ & $(-0.93,0.58)$ & 305.88 \\
\hline Minimum & 32 & $15(46.88)$ & $(0.46,1.77)$ & $7(21.88)$ & $(-3.87,-0.20)$ & $10(31.25)$ & $(-1.14,0.26)$ & 276.23 \\
\hline Average & 32 & $14(43.75)$ & $(0.73,2.11)$ & $7(21.88)$ & $(-4.55,-1.01)$ & $11(34.38)$ & $(-1.12,0.68)$ & 328.94 \\
\hline \multicolumn{9}{|c|}{ Relative humidity } \\
\hline Maximum & 32 & $14(43.75)$ & $(0.57,1.86)$ & $8(25.00)$ & $(-3.94,-0.41)$ & $10(31.25)$ & $(-1.00,0.87)$ & 272.83 \\
\hline Minimum & 32 & $13(40.63)$ & $(0.72 .1 .41)$ & $6(18.75)$ & $(-3.97,-0.60)$ & $13(40.63)$ & $(-1.09,1.41)$ & 291.87 \\
\hline Average & 32 & $15(46.88)$ & (0.52. 1.87) & $8(25.00)$ & $(-4.48,-0.29)$ & $9(28.13)$ & $(-0.46,0.43)$ & 256.35 \\
\hline \multicolumn{9}{|c|}{ Sea level pressure } \\
\hline Maximum & 32 & $9(28.13)$ & $(0.44,2.09)$ & 7 (21.88) & $(-4.59,-0.69)$ & $16(50.00)$ & $(-0.20,1.85)$ & 299.55 \\
\hline Minimum & 32 & $14(43.75)$ & $(0.46,1.85)$ & $8(25.00)$ & $(-4.27,-0.46)$ & $10(31.25)$ & $(-0.62,1.85)$ & 328.66 \\
\hline Average & 32 & $17(53.13)$ & $(0.46,1.75)$ & $8(25.00)$ & $(-5.32,-0.24)$ & $7(21.88)$ & $(-0.24,0.37)$ & 277.08 \\
\hline \multicolumn{9}{|l|}{ Wind speed } \\
\hline Maximum & 32 & $15(46.88)$ & $(0.25,2.28)$ & $6(18.75)$ & $(-4.88,-0.53)$ & $11(34.38)$ & $(-1.22,0.73)$ & 327.43 \\
\hline Average & 32 & $14(43.75)$ & $(0.40,1.71)$ & $9(28.13)$ & $(-4.71,-0.55)$ & $9(28.13)$ & $(-0.34,0.61)$ & 296.03 \\
\hline Rainfall & 32 & $17(53.13)$ & $(0.45,1.65)$ & 7 (21.88) & $(-4.74,-0.23)$ & $8(25.00)$ & $(-0.87,0.20)$ & 282.23 \\
\hline
\end{tabular}

Abbreviation: logRR The logarithm of relative risk, GD\% Geographic disparity percentage

coast of South America [21]. Based on their modeling estimations, Colombia may have at least 10 million populations potentially exposed to ZIKV. The spatial variation of ZIKV in Colombia indeed has been verified in the literature [37-39], while no direct evidence shows that the spatial variation of ZIKV was associated with climate change. Our findings on the best meteorological predictors are consistent with the results of a previous study, which analyzed the data in the whole Latin America [40]. In this study, the meteorological predictors can only explain 36-39\% of the spatial variation of ZIKV, revealing that there are still additional non-meteorological factors which can explain the spatial variation of ZIKV. This scenario emphasizes the importance of having a specific function to quantify the spatial variation that is not explained by meteorological measurements, like what the geospatial function can contribute in our models.

The risk factors responsible for emergence and the continued occurrence of ZIKV infection are not limited to meteorological factors. Biomedical research has proven that ZIKV can also be transmitted sexually [41-43]. Environmental and social changes, such as land use and human movement like tourism and immigration, might also be potential risk factors for
ZIKV epidemics [43]. These potential risk factors are difficult to obtain and aggregate by location and time in a spatiotemporal analysis. Ignoring these unobserved risk factors might hide their influence on ZIKV infection in some areas. Thus, our final model included a geospatial function to catch the proportion of ZIKV incidence unexplained by meteorological factors, resulting in two departments (Arauca and Meta) with excessive risk of ZIKV after controlling for the average temperature and total rainfall. In particular, average temperature was significantly associated with ZIKV in Arauca in Fig. 3, but both meteorological factors were not significantly associated with ZIKV in Meta. This finding indicates the importance of having an additional geospatial function to detect at-risk areas which cannot be detected by meteorological factors. In fact, previous studies have explored nonmeteorological risk factors of ZIKV. A risk assessment study of ZIKV applied a hierarchical approach to evaluate climate and nature factors as well as nonmeteorological risk dimensions of ZIKV, resulting in that mosquito densities and epidemics of dengue fever are more related to ZIKV transmission than climate and nature factors [44]. Sexual contact has been also 


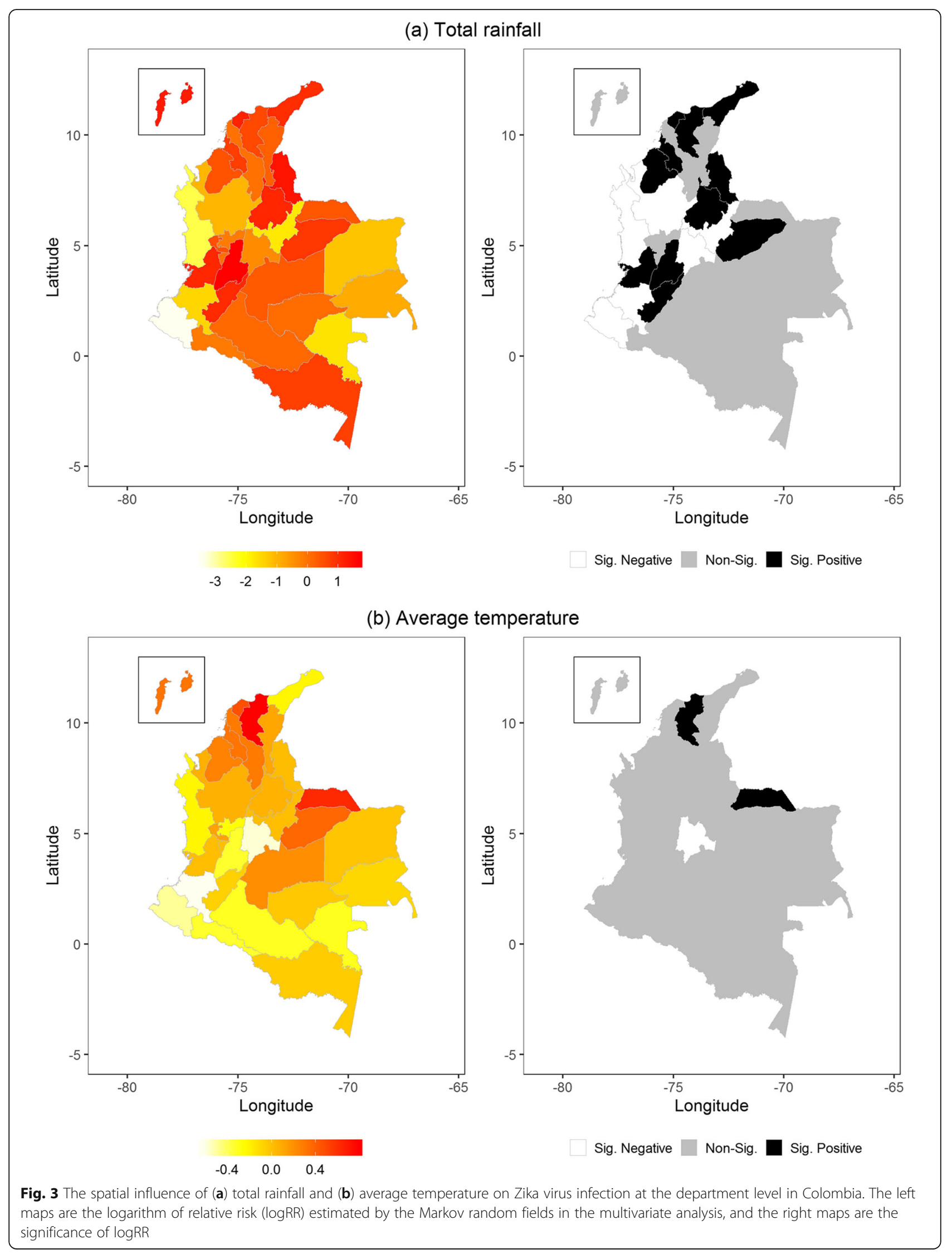



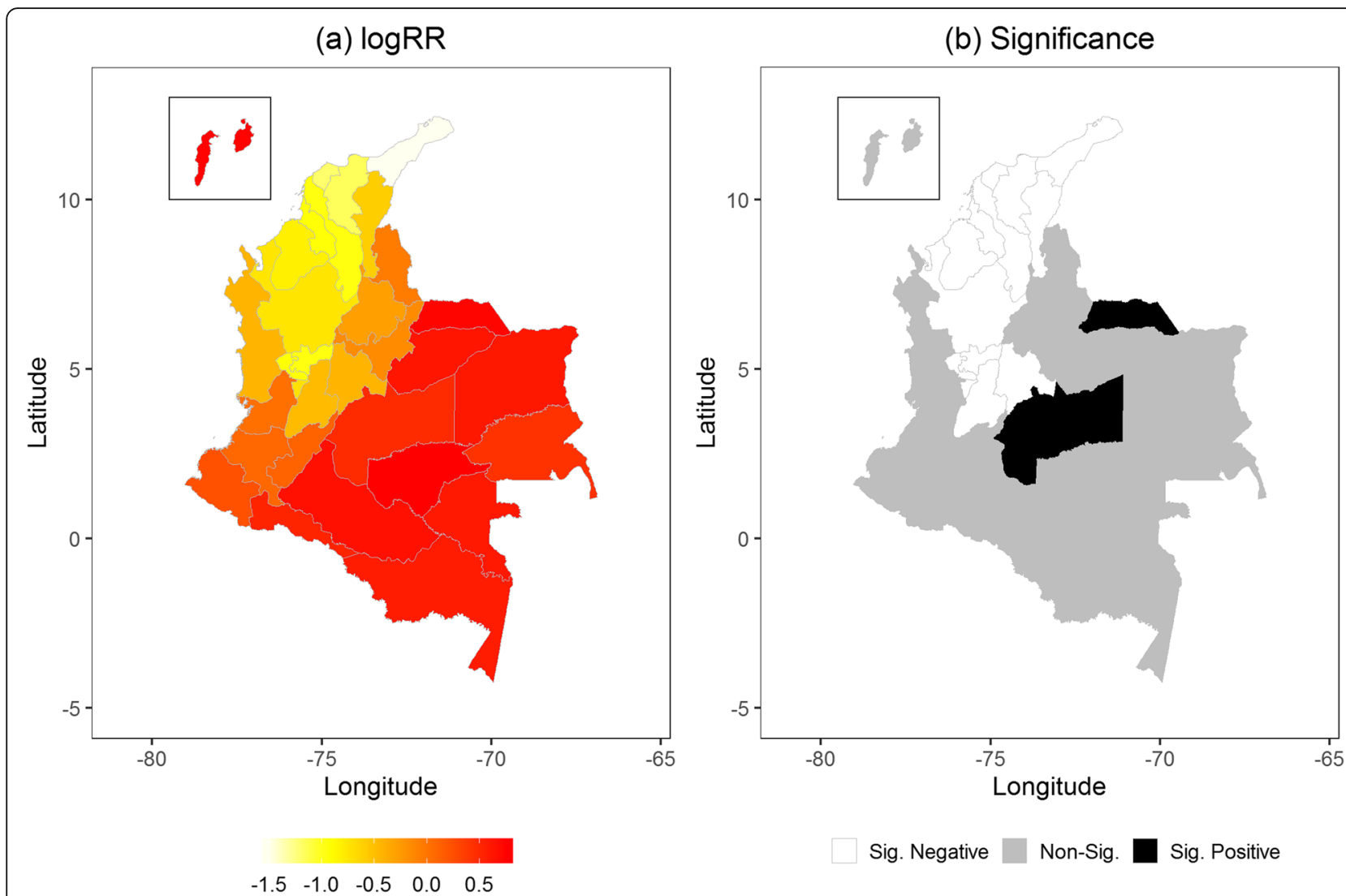

Fig. 4 The spatial distribution of (a) the logarithm of relative risk (logRR) estimated from the geospline function and (b) the significance of logRR. Both are based on the multivariate analysis

verified to be a plausible transmission pathway by case reports $[45,46]$, despite the fact that results from other laboratory experiments and simulation research are inconsistent [47-49]. To concern the difficulties of collecting non-meteorological data as confounding factors matching the daily ZIKV cases and meteorological measurements by date and department, adding an independent geospatial function in the model provides the rationale of better taking those unobserved risk factors into account.

This study has three main limitations. First, we applied the DIC to select average temperature and total rainfall as the best meteorological predictors to explain the geographic disparities of ZIKV infection, while no Rsquared measurement can be calculated to exactly know the explained percentage based on the methodology of the Bayesian model. Second, current ZIKV data were only released based on department, which is not the smallest administrative area in Colombia. Meanwhile, the study is unable to evaluate further risk patterns inside those high risk departments identified by our models. Third, we do not know if the excessive ZIKV cases were imported, so further research is needed because the current database does not distinguish domestic and imported ZIKV cases.

\section{Conclusions}

Although ZIKV infection has gradually decreased since 2017, there is a threat of the resurgence of ZIKV because no effective vaccine or antiviral drugs have been developed yet. The best strategy to confront ZIKV is to implement preventive interventions. The findings of this study can be used by governmental agencies to devote their prevention efforts in identified high risk areas where meteorological factors can predict the increase of ZIKV infections. By combining meteorological factors with a real-time weather monitoring system, future work is to predict possible outbreaks of ZIKV earlier, and to provide timely surveillance and assistance in areas with vulnerable populations.

\section{Supplementary information}

Supplementary information accompanies this paper at https://doi.org/10. 1186/s12879-019-4499-9.

Additional file 1. The supplementary materials with a correlation matrix among meteorological measurements, the geographic distribution maps of the averages of meteorological measurement, and the spatial estimates with corresponding significance from the Markov random fields in the univariate analysis. 


\section{Abbreviations}

Cl: Credible interval; DIC: Deviance information criterion; GD\%: Geographic disparity percentage; logRR: Logarithm of relative risk; MRF: Markov random fields; ZIKV: Zika virus

\section{Acknowledgments}

We thank the data support from the Epidemiological Bulletin maintained by the Instituto Nacional de Salud in Colombia.

\section{Declarations}

The findings and conclusions in this report are those of the authors and do not necessarily represent the official position of the funding agencies.

\section{Authors' contributions}

LCC designed the study, collected and analyzed the data, and wrote the manuscript. FS edited and revised the manuscript. AP collected the data and revised the manuscript. All authors read and approved the final manuscript.

\section{Funding}

The study was supported by the University of Nevada, Las Vegas, the University of Texas Health Science Center at Houston-UTHealth, and the Michael \& Susan Dell Foundation [Grant 8075] during the writing of this manuscript. The funding of the three institutes was not involved in the design of the study, data collection, data analysis, interpretation, and the writing of this manuscript.

\section{Availability of data and materials}

Please contact the corresponding author for data requests.

\section{Ethics approval and consent to participate}

The study protocol was approved by the Institutional Review Board at the University of Texas Health Science Center at Houston-UTHealth (IRB No. HSC$\mathrm{SPH}-16-0959)$. There is no administrative permission to access the raw data.

\section{Consent for publication}

Consent for publication was obtained from all authors.

\section{Competing interests}

The authors declare that they have no competing interests.

\section{Author details}

${ }^{1}$ Department of Environmental and Occupational Health, University of Nevada, Las Vegas, School of Public Health, 4505 S. Maryland Parkway, Las Vegas, NV 89154, USA. ${ }^{2}$ Department of Biostatistics and Data Science, The University of Texas Health Science Center at Houston-UTHealth, School of Public Health, Austin Campus, 1616 Guadalupe, Suite 6.300, Austin, TX 78071, USA.

\section{Received: 25 March 2019 Accepted: 23 September 2019}

\section{Published online: 24 October 2019}

\section{References}

1. Vasconcelos PFC, Powers AM, Hills S. Chapter 7 - the emergence of chikungunya and Zika viruses in the Americas. In: Higgs S, Vanlandingham DL, Powers AM, editors. Chikungunya and Zika Viruses. Cambridge: Academic Press; 2018. p. 215-35.

2. Ryan SJ, Carlson CJ, Stewart-Ibarra AM, Borbor-Cordova MJ, Romero MM, Cox S-A, Mahon R, Trotman A, St Ville S, Ahmed S. Outbreak of Zika virus infections, Dominica, 2016. Emerg Infect Dis. 2017;23(11):1926-7.

3. Zika Virus - Symptoms, Testing \& Treatment. https://www.cdc.gov/zika/ symptoms/symptoms.html. Accessed 11 Oct 2018.

4. Mlakar J, Korva M, Tul N, Popović M, Poljšak-Prijatelj M, Mraz J, Kolenc M, Resman K, Vesnaver Vipotnik T, Fabjan Vodušek V, Vizjak A, Pižem J, Petrovec M, Avšic Ž ŽT. Zika virus associated with microcephaly. N Engl J Med. 2016;374(10):951-8.

5. Kolikonda MK, Srinivasan K, Enja M, Sagi V, Lippmann S. Zika microcephaly. Innov Clin Neurosci. 2017;14(9-10):11-2.

6. Squiers L, Herrington J, Kelly B, Bann C, Becker-Dreps S, Stamm L, Johnson M, McCormack L. Zika virus prevention: U.S. Travelers' knowledge, risk perceptions, and behavioral intentions-a national survey. Am J Trop Med Hyg. 2018;98(6):1837-47.
7. Darrow W, Bhatt C, Rene C, Thomas L. Zika virus awareness and prevention practices Among University students in Miami: fall 2016. Health Educ Behav. 2018;45(6):967-76.

8. Hamer DH, Wilson ME, Jean J, Chen LH. Epidemiology, prevention, and potential future treatments of sexually transmitted Zika virus infection. Curr Infect Dis Rep. 2017;19(4):16.

9. World Health Organization. Comprehensive guideline for prevention and control of dengue and dengue haemorrhagic fever. 2011.

10. Mohammed A, Chadee DD. Effects of different temperature regimens on the development of Aedes aegypti (L.) (Diptera: Culicidae) mosquitoes. Acta Trop. 2011;119(1):38-43.

11. Yang HM, Macoris ML, Galvani KC, Andrighetti MT, Wanderley DM. Assessing the effects of temperature on the population of Aedes aegypti, the vector of dengue. Epidemiol Infect. 2009;137(8):1188-202.

12. Tran A, L'Ambert G, Lacour G, Benoit R, Demarchi M, Cros M, Cailly P, Aubry-Kientz M, Balenghien T, Ezanno P. A rainfall- and temperaturedriven abundance model for Aedes albopictus populations. Int J Environ Res Public Health. 2013;10(5):1698-719.

13. Yi B, Zhang Z, Xu D, Xi Y, Fu J, Luo J, Yuan M, Liu S, Zuo Z. Relationship of dengue fever epidemic to Aedes density changed by climate factors in Guangdong Province. Wei Sheng Yan Jiu. 2003;32(2):152-4.

14. Gleiser RM, Urrutia J, Gorla DE. Body size variation of the floodwater mosquito Aedes albifasciatus in Central Argentina. Med Vet Entomol. 2000; 14(1):38-43.

15. Rochlin I, Ninivaggi DV, Hutchinson ML, Farajollahi A. Climate change and range expansion of the Asian tiger mosquito (Aedes albopictus) in northeastern USA: implications for public health practitioners. PLoS One. 2013;8(4):e60874.

16. Hales S, de Wet N, Maindonald J, Woodward A. Potential effect of population and climate changes on global distribution of dengue fever: an empirical model. Lancet. 2002;360(9336):830-4.

17. Hopp MJ, Foley JA. Global-scale relationships between climate and the dengue fever vector, Aedes aegypti. Clim Change. 2001;48(2-3):441-63.

18. Aguiar BS, Lorenz C, Virginio F, Suesdek L, Chiaravalloti-Neto F. Potential risks of Zika and chikungunya outbreaks in Brazil: a modeling study. Int J Infect Dis. 2018;70:20-9.

19. Weber AV. Exploring local influences on Zika virus rates in Puerto Rico utilizing geographically weighted regression. Papers in Appl Geogr. 2018; 4(1):100-12

20. Asher J, Barker C, Chen G, Cummings D, Chinazzi M, Daniel-Wayman S, Fischer M, Ferguson N, Follman D, Halloran ME, Johansson M, Kugeler K, Kwan J, Lessler J, Longini IM, Merler S, Monaghan A, Pastore y Piontti A, Perkins A, Prevots DR, Reiner R, Rossi L, Rodriguez-Barraquer I, Siraj AS, Sun K, Vespignani A, Zhang Q. Preliminary results of models to predict areas in the Americas with increased likelihood of Zika virus transmission in 2017. bioRxiv. 2017:187591. https://doi.org/10.1101/187591.

21. Alaniz AJ, Bacigalupo A, Cattan PE. Spatial quantification of the world population potentially exposed to Zika virus. Int J Epidemiol. 2017; 46(3):966-75.

22. Jiang D, Hao M, Ding F, Fu J, Li M. Mapping the transmission risk of Zika virus using machine learning models. Acta Trop. 2018;185:391-9.

23. Review World Population: Bogota Population. http://worldpopulationreview. com/world-cities/bogota/. Accessed 3 Jan 2019.

24. Liang D, Kumar N. Time-space kriging to address the spatiotemporal misalignment in the large datasets. Atmos Environ. 2013;72:60-9.

25. Fahrmeir L, Osuna EL. Structured additive regression for overdispersed and zero-inflated count data. Appl Stoch Model Bus Ind. 2006;22(4):351-69.

26. Fahrmeir L, Kneib T, Lang S. Penalized structured additive regression for space-time data: a Bayesian perspective. Stat Sin. 2004;14(3):731-61.

27. Development R, Core Team. R: a language and environment for statistical computing. Vienna: R Foundation for Statistical Computing; 2011.

28. Brezger A, Kneib T, Lang S. BayesX: Analysing Bayesian structured additive regression models. J Stat Softw. 2005;14(11):1-22.

29. Zika Virus Vaccines. https://www.niaid.nih.gov/diseases-conditions/zikavaccines. Accessed 20 Nov 2018.

30. Singh RK, Dhama K, Khandia R, Munjal A, Karthik K, Tiwari R, Chakraborty S, Malik YS, Bueno-Marí R. Prevention and control strategies to counter Zika virus, a special focus on intervention approaches against vector mosquitoes-current updates. Front Microbiol. 2018;9:87.

31. Plourde AR, Bloch EM. A literature review of Zika virus. Emerg Infect Dis. 2016;22(7):1185 
32. Barrera R, Amador M, Acevedo V, Beltran M, Muñoz JL. A comparison of mosquito densities, weather and infection rates of Aedes aegypti during the first epidemics of chikungunya (2014) and Zika (2016) in areas with and without vector control in Puerto Rico. Med Vet Entomol. 2018:33:68-77.

33. Nance J, Fryxell RT, Lenhart S. Modeling a single season of Aedes albopictus populations based on host-seeking data in response to temperature and precipitation in eastern Tennessee. J Vector Ecol. 2018;43(1):138-47.

34. Wu X, Lang L, Ma W, Song T, Kang M, He J, Zhang Y, Lu L, Lin H, Ling L. Non-linear effects of mean temperature and relative humidity on dengue incidence in Guangzhou, China. Sci Total Environ. 2018;628-629:766-71.

35. Hii YL, Zaki RA, Aghamohammadi N, Rocklöv J. Research on climate and dengue in Malaysia: a systematic review. Curr Environ Health Rep. 2016;3(1):81-90.

36. Zambrana JV, Bustos Carrillo F, Burger-Calderon R, Collado D, Sanchez N Ojeda S, Carey Monterrey J, Plazaola M, Lopez B, Arguello S, Elizondo D, Aviles W, Coloma J, Kuan G, Balmaseda A, Gordon A, Harris E. Seroprevalence, risk factor, and spatial analyses of Zika virus infection after the 2016 epidemic in Managua, Nicaragua. Proc Natl Acad Sci U S A. 2018; 115(37):9294-9.

37. Perkins TA, Rodriguez-Barraquer I, Manore C, Siraj ASEspãna G, Barker CM Reiner RC, Heterogeneous local dynamics revealed by classification analysis of spatially disaggregated time series data. Epidemics. 2019. https://doi.org/ 10.1016/j.epidem.2019.100357.

38. Martínez-Bello D, López-Quílez A, Torres PA. Spatio-temporal modeling of Zika and dengue infections within Colombia. Int J Environ Res Public Health. 2018;15(7):1376.

39. Chien L-C, Lin R-T, Liao Y, Sy FS, Pérez A. Surveillance on the endemic of Zika virus infection by meteorological factors in Colombia: a population-based spatial and temporal study. BMC Infect Dis. 2018;18(1):180.

40. Harris MJ, Caldwell JM, Mordecai EA. Climate drives spatial variation in Zika epidemics in Latin America. Proc R Soc Lond [Biol]. 2019;286(1909): 20191578.

41. Mansuy JM, Dutertre M, Mengelle C, Fourcade C, Marchou B, Delobel P, Izopet J, Martin-Blondel G. Zika virus: high infectious viral load in semen, a new sexually transmitted pathogen. Lancet Infect Dis. 2016;16(4):405.

42. Atkinson B, Hearn P, Afrough B, Lumley S, Carter D, Aarons EJ, Simpson AJ Brooks TJ, Hewson R. Detection of Zika virus in semen. Emerg Infect Dis. 2016;22(5):940

43. Ali S, Gugliemini O, Harber S, Harrison A, Houle L, Ivory J, Kersten S, Khan R, Kim J, LeBoa C, Nez-Whitfield E, O'Marr J, Rothenberg E, Segnitz RM, Sila S, Verwillow A, Vogt M, Yang A, Mordecai EA. Environmental and social change drive the explosive emergence of Zika virus in the Americas. PLoS Negl Trop Dis. 2017;11(2):e0005135.

44. Li X, Liu T, Song T, Du X, Lin H, Xiao J, He J, Liu L, Zhu G, Zeng W, Guo L, Cao Z, Ma W, Zhang Y. Application of the analytic hierarchy approach to the risk assessment of Zika virus disease transmission in Guangdong Province. China BMC Infect Dis. 2017;17(1):65.

45. Mead PS, Hills SL, Brooks JT. Zika virus as a sexually transmitted pathogen. Curr Opin Infect Dis. 2018:31:39-44.

46. Davidson A, Slavinski S, Komoto K, Rakeman J, Weiss D. Suspected female-tomale sexual transmission of Zika virus-New York City, 2016. MMWR Morb Mortal Wkly Rep. 2016;65:716-7.

47. Gao D, Lou Y, He D, et al. Prevention and control of Zika as a mosquito-borne and sexually transmitted disease: a mathematical modeling analysis. Sci Rep. 2016;6:28070.

48. Allard A, Althouse BM, Hébert-Dufresne L, Scarpino SV. The risk of sustained sexual transmission of Zika is underestimated. PLoS Pathog. 2017;13:e1006633.

49. Yakob L, Kucharski A, Hue S, Edmunds WJ. Low risk of a sexually-transmitted Zika virus outbreak. Lancet Infect Dis. 2016;16:1100-2.

\section{Publisher's Note}

Springer Nature remains neutral with regard to jurisdictional claims in published maps and institutional affiliations.

Ready to submit your research? Choose BMC and benefit from:

- fast, convenient online submission

- thorough peer review by experienced researchers in your field

- rapid publication on acceptance

- support for research data, including large and complex data types

- gold Open Access which fosters wider collaboration and increased citations

- maximum visibility for your research: over $100 \mathrm{M}$ website views per year

At BMC, research is always in progress.

Learn more biomedcentral.com/submissions 